\title{
CLIL in Practice in Japanese Elementary Classrooms: An Analysis of the Effectiveness of a CLIL Lesson in Japanese Traditional Crafts
}

\author{
Yukiko Ito ${ }^{1}$ \\ ${ }^{1}$ Faculty of Management, Osaka Seikei University, Osaka, Japan \\ Correspondence: Yukiko Ito, Faculty of Management, Osaka Seikei University, Osaka, 3-10-62, Aikawa, \\ Higashiyodogawa-ku, Osaka, 533-0007, Japan. Tel: 81-6829-2600. E-mail: itoh-yu@osaka-seikei.ac.jp
}

Received: July 1, 2018 Accepted: August 8, 2018 Online Published: August 10, 2018

doi: 10.5539/elt.v11n9p59 URL: http://doi.org/10.5539/elt.v11n9p59

\begin{abstract}
This study focuses on how elementary school students learn and think about the development and sustainability of Japanese traditional crafts through a CLIL lesson. The Japanese Course of Study (MEXT, 2017) emphasizes the importance of fostering regionalism and the development of Japanese traditional culture. This plays a significant role in global education. Students must have the knowledge, ability and the will to talk about Japanese culture to non-Japanese people in English. Fostering student's cross-cultural understanding is crucial to achieve this. The researcher carried out the CLIL lesson with a total of 175 elementary students in Nara, Japan. The students were given instruction in the history, the present situation and the construction of Nara Fans, which are a traditional product of Japan. The results show that students were able to use various English target expressions during the lesson and were not bothered about whether the lesson was in Japanese or English but instead concentrated on the lesson content. In addition, the students learned that Nara is popular among foreigners and that there are many ruins in their surrounding area. In conclusion, CLIL lessons should be continued in various subjects, while taking into consideration individual support for each student, and the importance of constant verification of lesson targets and content.
\end{abstract}

Keywords: CLIL, cross-cultural education, Japanese traditional crafts, elementary school, Nara Fans

\section{Introduction}

\subsection{Background}

Currently, various English education policies are being considered in Japan. According to the new Course of Study (MEXT, 2017) which will be fully implemented from 2020, it is important to learn a foreign language through "interaction". Schoolteachers search for effective instruction methods which foster deeper learning through the verbal exchange of thoughts and ideas. In addition, the Course of Study mentions the importance of fostering regionalism and development of traditional culture. Students need to have the knowledge and will to talk about Japanese culture in the target language. Keeping these points in mind, what kind of lesson would be beneficial?

In this study, the researcher focuses on CLIL (Content and Language Integrated Learning). CLIL is "a dual-focused educational approach in which an additional language is used for the learning and teaching of both content and language" (Coyle, Hood, \& Marsh, 2010). One aim of CLIL is to foster cross-cultural understanding and general-purpose abilities as well as the acquisition of the target language (Ikeda, 2018). In addition, CLIL is also an indispensable tool for ESD (Education for Sustainable Development). It is important now and for the future that students have a deep understanding of the world and cultivate a wide range of knowledge.

\subsection{Purpose of the Current Study}

The purpose of the current study is (1) to develop, prepare and present a CLIL lesson instructing students how to make Nara Fans, which are a traditional product of Nara, Japan, and (2) to examine how elementary school students learn about Nara Fans and think about their development and sustainability through the CLIL lesson. The researcher investigated the following research questions (RQs).

RQ1: Did the students learn the target English vocabulary and expressions?

RQ2: Did the students learn about the history and use of Nara Fans? 
RQ3: How did the students learn about Japanese traditional crafts of Nara?

\section{Previous Study}

\subsection{CLIL (Content and Language Integrated Learning)}

Generally, CLIL is constructed with 4Cs which are: Content, Communication, Cognition, and Community/ Culture (Watanabe, Ikeda, \& Izumi, 2011).

In CLIL "A foreign language is used as a tool in the learning of a non-language subject in which both the language and the subject have a joint role" (Marsh, 2002). As CLIL is a subject-based teaching method, it is fundamentally different from foreign language teaching. CLIL lessons are also useful for progress in the learner's native language. It may motivate students, and much of the content of the lesson can be studied through CLIL (Sasajima, 2011).

It is vital that teachers create lessons in which students can immerse themselves in the lesson content without being concerned with the language of instruction. In CLIL, teachers communicate with students using English, but students who have just started to learn English often forget, or for various other reasons do not reciprocate in kind. When concentrating on content during a lesson, students often murmur in their native language, as it is natural for them to do so. Some researchers mention that as the learner's English improves, the amount of murmuring in their native language will decrease. (Sasajima, 2011; Kashiwagi, 2013).

Generally, CLIL lessons are designed covering four “C”'s: (Watanabe, Ikeda, \& Izumi, 2011). These are outlined in Table 1.

Table 1. 4Cs in CLIL curriculum

\begin{tabular}{ll}
\hline Content & $\begin{array}{l}\text { Progression in knowledge, skills and understanding related to specific elements of a defined } \\
\text { curriculum }\end{array}$ \\
\hline Communication & $\begin{array}{l}\text { Using language to learn whilst learning to use language } \\
\text { Developing thinking skills which link concept formation (abstract and concrete), } \\
\text { understanding and language }\end{array}$ \\
Cognition & $\begin{array}{l}\text { Exposure to alternative perspectives and shared understandings, which deepen awareness of } \\
\text { otherness and self. }\end{array}$ \\
\hline
\end{tabular}

(Coyle, 1999).

\subsection{Effectiveness of CLIL}

\subsubsection{Positive Arguments for CLIL}

Recently the use of CLIL has increased in Japan. Researches devoted to CLIL mention the following "good points of CLIL" (Yamano, 2013; Ito, 2018) through practices and investigations.

Students are less anxious about making mistakes in English as they are focused on lesson content.

Many students feel as though lessons are fun because their intellectual curiosity is fulfilled.

Many students feel that CLIL lessons are easy to understand as teachers tend to use visual aids.

Blocks of language (e.g. target phrases either in full or part) remain in students' memories, which often lead to utterances in English.

Instead of understanding by always translating English into Japanese, students can get into the habit of learning blocks of language as they are.

\subsubsection{From the Viewpoint of Language Acquisition}

Kashiwagi, et al. (2018) have focused on the effect of language acquisition using CLIL. Targeting second-grade Junior High School students in Japan, a teacher introduced a story in English and carried out lessons aiming to acquire the passive voice. Through a comparison of the CLIL group and the non-CLIL group, the researchers saw that the CLIL group was able to distinguish almost $100 \%$ of the passive voice expressions while the Non-CLIL group was significantly less successful. Although the Non-CLIL group had the grammar explained to them, they found it difficult to distinguish grammar errors which were presented to them. Based on these results, the positive arguments for CLIL in relation to language acquisition are listed below: 
Students acquire a high ability to judge whether a sentence in English is correct.

Students develop a feeling of discomfort when they are presented with a text that includes mistakes.

The rate of retention of English expressions used during the CLIL lesson is very high.

The rate of the learned English expressions used by students while thinking is high.

\section{Method}

\subsection{Participants}

The participants of this study are the fifth and sixth grade classes of a public elementary school in Nara, Japan. The classes consist of 101 fifth graders and 74 sixth graders (total 175 students). In this school, English instruction begins in the fifth grade, taught by homeroom teachers and an ALT (Assistant Language Teacher) one hour a week. Most of the students enjoy English classes, but the level of understanding varies from student to student. As the content of the lesson involves history as well as each student using their own cutter knife, it was decided that the participants should be in the higher grades of elementary school. The lesson was carried out by four instructors including the researcher. During the CLIL lesson, the homeroom teacher was there to help and support the students.

\subsection{Materials}

The post-test concerning the history, use and the current succession crisis of Nara Fan manufacturers is adapted here. A descriptive questionnaire was also used in this study. To measure students' understanding of the English expressions taught and the contents of the lesson, the following questions were conducted. Questions 1 to 4 tested the students on the lesson content. For Q5 to Q11 students were given a Likert scale with which to express their answers: 4: strongly agree, 3: agree, 2: disagree, 1: strongly disagree, while Q12 and Q13 encouraged students to write their answers freely.

(1) When were Nara Fans made for the first time?

(2) Who made Nara Fans for the first time?

(3) What kind of characteristics do Nara Fans have?

(4) Fill in the blank. Nara Fans are made in ( ).

(5) Did you enjoy today's lesson?

(6) Do you like English classes?

(7) Do you like history classes?

(8) Do you like arts and crafts classes?

(9) Did you understand the lesson content in English?

(10) Did you understand the history of Nara Fans?

(11) Did you understand how to make your Nara Fan?

(12) How was today's lesson?

(13) What did you learn from the lesson?

\subsection{Research Procedure}

The Nara Fan lesson described above was held by the instructors in February 2018. The following week the post-test was conducted, and the questionnaires were filled out by the participants. This data was analyzed both quantitatively and qualitatively. Qualitative analysis was performed using Steps for Coding and Theorization: SCAT (Otani, 2011). The analytical procedure of SCAT consists of four coding steps:

(1) To isolate words and phrases which should be given special attention.

(2) To find words and phrases that can be used as replacements from the outside of the data (1).

(3) To find words and phrases which explain the words in step (1) and (2).

(4) To figure out the themes and constructs from step (1), (2) and (3), and construct a theory and a story line.

The entire process was recorded in the SCAT matrix. The SCAT method was used due to it being useful for small scale data. 


\subsection{Lesson Procedure}

This lesson has the following two aims: (1) for the students to learn the target words and sentences of the lesson, and (2) to focus on whether students can pay attention to lesson content in English. Table 2 shows the 4Cs in this lesson.

Table 2. 4Cs of the Nara Fan CLIL lesson

\begin{tabular}{ll}
\hline Content & $\begin{array}{l}\text { To learn the history and the use of Nara Fans. } \\
\text { To learn the present situation of Nara Fan craftsmen. } \\
\text { To become familiar with the structure and materials of the fan and to make their own } \\
\text { Nara Fan. }\end{array}$ \\
\hline Communication & $\begin{array}{l}\text { To repeat the target sentences and expressions: } \\
\text { Nara Fan, Nara Period, priest, evil, put, cut, paste, Nara Fans are made in Nara. }\end{array}$ \\
\hline Cognition & $\begin{array}{l}\text { To design an image of a deer native to Nara. } \\
\text { To think about how to design and create a fan. }\end{array}$ \\
\hline Culture & To make a fan in a group setting. \\
& To learn about Nara Fans which are a traditional product of Nara. \\
& To become aware of the relationship between Nara and foreign countries. \\
\hline
\end{tabular}

Before the CLIL lesson began, the instructors gave technical guidance in the use of cutter knives. The lesson covered two 45 minutes periods with a ten-minute break in between, although most of the students worked on their fans through the break. In the first period, using presentation slides, the instructors showed pictures of a fan drawn along with an image of the remains of Asuka-village in Nara. Then the instructors stated when Nara Fans were first made and how they were used, and the situation of the current Nara Fan craftsman. In the second period, students began to make their individual Nara Fans. During the lesson done in February 2018, the students were required to draw a deer, as deer are a symbol of Nara. The post-lesson test and the questionnaires were held in the third period the week after (Table 3).

Table 3. Lesson Schedule of the CLIL lesson

\begin{tabular}{lll}
\hline Lesson & Activities & Test \& Questionnaires \\
\hline Prior instruction & Instruction in the use of cutter-knives & \\
The first lesson & Introduction: Presentation of the history and use of Nara & \\
& Fans. Show a Nara Fan sample. & \\
The second lesson & Craft lesson- making Nara Fans. & Post-test, Questionnaires \\
\hline
\end{tabular}

\subsection{Narrative Descriptions of the Lessons}

The instructor showed slides illustrating the history and use of Nara Fans and the problem of the lack of successors. The content can be perceived difficult, so the comprehension quiz consisted mainly of "What is this?", "Where is this place?", "How many years ago?" Students enjoyed participating in this part of the lesson while talking and thinking with their classmates. Although the students were not forbidden to speak in Japanese, the teacher always replied in English. Some of the students answered the questions posed in the lesson in English.

Since Nara Fans are manufactured only in Nara, the teacher repeated the expression "Nara Fans are made in Nara," and emphasized its status as a traditional craft of Nara. Next, the teacher explained the elaborate process of designing and making the fans. Next, each student designed an image of a deer (Figure 1,2). While the teacher was explaining using English phrases such as "Put these two washi papers together," "Cut the washi-paper with the cutter knife," or "Paste one paper to each side of the bamboo frame", students were nodding. At the end of 
the lesson, the teacher reviewed the history, use, and the present situation of Nara Fan craftsman succession once again using "when", "where", "who" and "how". Students remembered the information well.

The third lesson was held after one week's time. Along with the ALT, the homeroom teacher reviewed in English the history and phrases learned. At the end of the lesson, the questionnaire was handed out and the post-test was conducted. Although English input was oral with no reading or writing activities, there were many students filling in phrases such as "Nara Fan", "Japan", and "Kasuga Taisha" in English. From the questionnaire, the researcher concluded that the students understood the content very well: they were aware that there is only one producer of Nara Fans remaining, and that the craft is experiencing a succession crisis. Throughout the class, students thought about various aspects of Nara Fans and were observed muttering utterances about Nara Fans in both English and their native language (Japanese). Figure 1 and Figure 2 show students cutting out their designs.

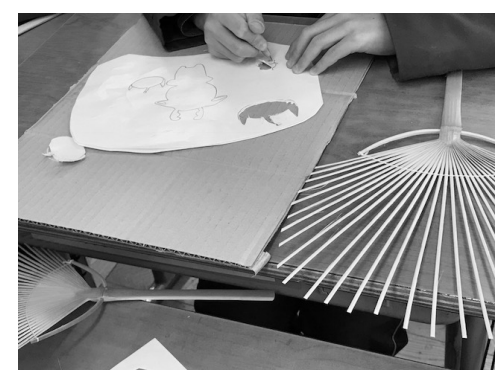

Figure 1

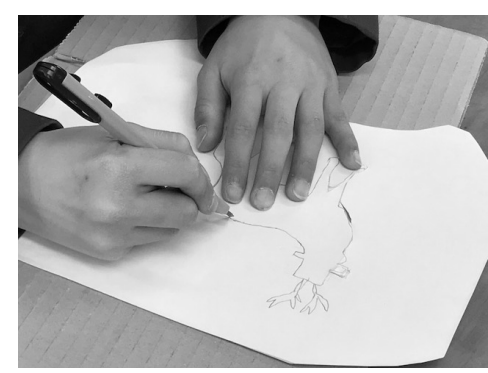

Figure 2

\section{Analysis}

\subsection{Quantitatively Analysis}

\subsubsection{Test Part}

To investigate the students understanding of the lesson content, the researcher conducted a post-test and each student filled out a questionnaire $(N=175)$. The results of the post-test are shown in Table 4.

Table 4. Correct answer rate of the 4 post-test questions ( $N=175)$

\begin{tabular}{lc}
\hline Questions & Correct answer rate \\
\hline Q (1) When & $70.9 \%$ \\
Q (2) Who & $72.6 \%$ \\
Q (3) Characteristic & $56.0 \%$ \\
Q (4) Nara Fans are made in ( $\quad)$ & $58.3 \%$ \\
\hline
\end{tabular}

(1) and (2) in Table 4 and Figure 3 show that more than $70 \%$ of students understood very well the history of Nara Fans. Results for question (3), however, clearly show that the level of comprehension was much lower as there were many different answers written. The reason for this is unclear: were there many different answers written because Nara Fans have many distinctive characteristics, or did the students have difficulty understanding the meaning of the word "characteristic"? Nearly $60 \%$ of students answered question (4) correctly. Although in their English classes they had not yet studied the passive voice, due to repetition during the lesson the students retained the expression "made in ..." and were able to remember and use it a week later in the follow up class. 


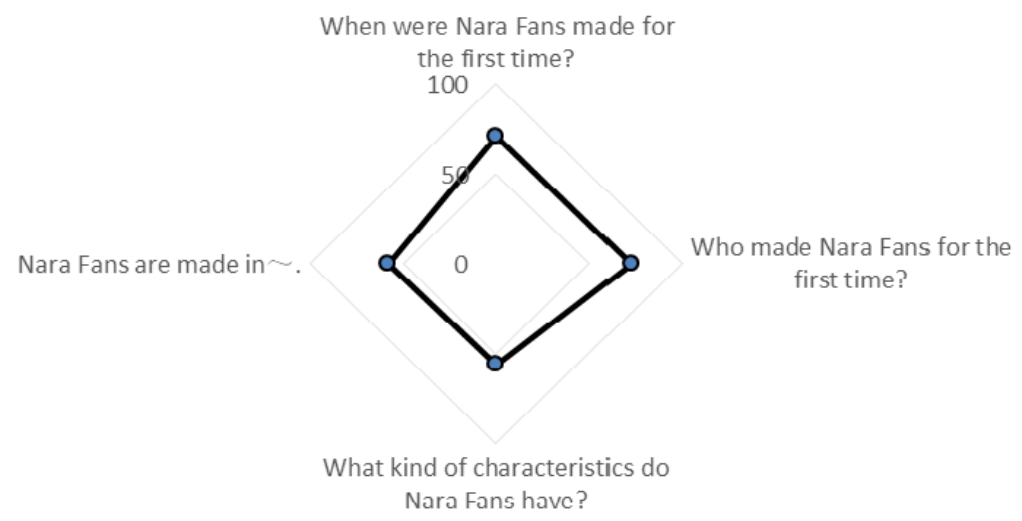

Figure 4. Radar chart of post-test results

\subsubsection{Questionnaire Part}

Descriptive statistics of the questionnaire are shown in Table 5 while the radar chart in Figure 4 and the box plot in Figure 5 illustrate the students' responses. As shown in these graphs, question (6) is of a lower numerical value compared to other questions. Although the fifth and sixth graders at the elementary school where the CLIL lesson was conducted have English classes every week, it is apparent that there are some students who struggle with English more than others. However, although the lesson was conducted entirely in English, Figure 5 indicates that the rate of students who enjoyed the lesson (see question "Did you enjoy today's lesson?") was much higher than the rate of students who expressed that they like English classes (see question 6 "Do you like English classes?"). This leads the researcher to conclude that CLIL lessons also have value for those students who are weak in and/or dislike English. Table 6 shows results of the comparison between the responses to questions (5) Did you enjoy today's lesson? and (6) Do you like English classes? When comparing the two, the numbers are significantly different. From these results it can be concluded that students who do not particularly like English classes expressed that they enjoyed this CLIL lesson.

Table 5. Descriptive statistics of the questionnaire $(N=175)$

\begin{tabular}{llllll}
\hline & Mean & Max & Min & SD & SE \\
\hline (5) Did you enjoy today's lesson? & 3.27 & 4 & 1 & .706 & .053 \\
(6) Do you like English classes? & 2.54 & 4 & 1 & .814 & .061 \\
(7) Do you like history classes? & 2.93 & 4 & 1 & .950 & .071 \\
(8) Do you like arts and crafts classes? & 3.23 & 4 & 1 & .828 & .062 \\
(9) Did you understand the lesson content in English? & 2.7 & 4 & 1 & .795 & .060 \\
(10) Did you understand the history of Nara Fans? & 2.86 & 4 & 1 & .793 & .599 \\
(11) Did you understand how to make your Nara Fan? & 2.79 & 4 & 1 & .839 & .063 \\
\hline
\end{tabular}

Table 6 Results of the T-test $(N=175)$

\begin{tabular}{lllll}
\hline & t-value & $\mathrm{p}$-value & $\mathrm{df}$ & Cohen's d \\
\hline (5) Did you enjoy today's lesson? & 11.83 & $\mathrm{P}<0.001^{* *}$ & 174 & .96 \\
(6) Do you like English classes? & & & & \\
\hline
\end{tabular}




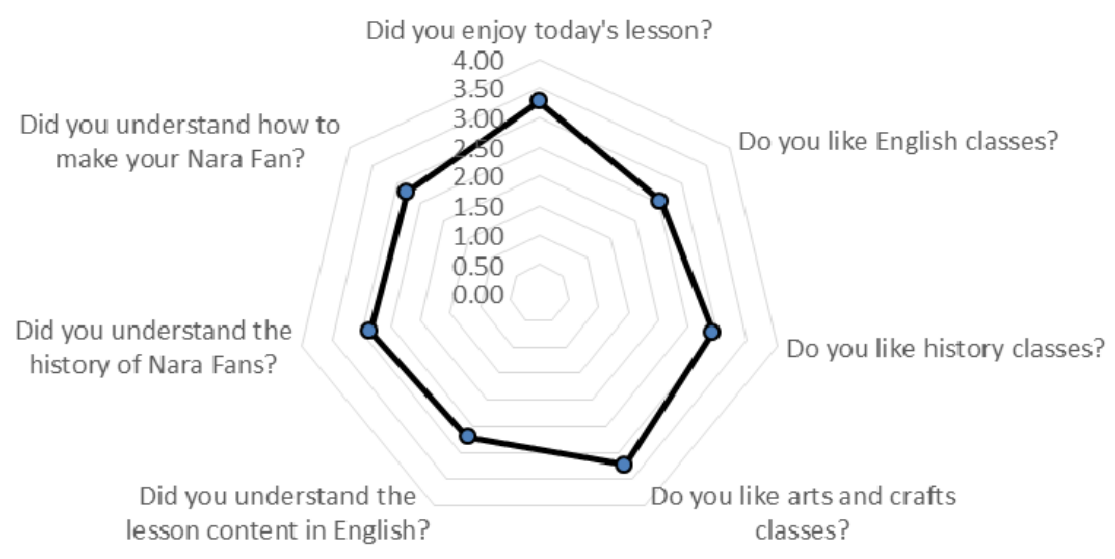

Figure 4. Radar chart of the questionnaire

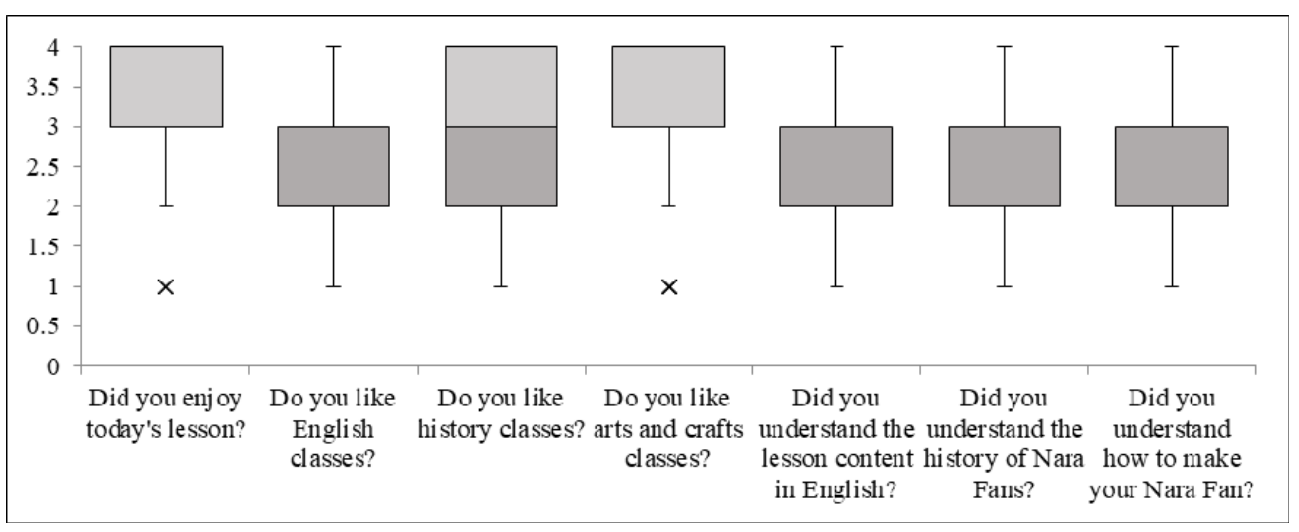

Figure 5. Box plot of the questionnaire $(N=175)$

\subsection{Qualitative Analysis}

In the post-lesson questionnaire, students were asked "What did you learn from the lesson?" Using SCAT as an analysis tool, the following story line is drawn.

The Story Line: The students understood when and why Nara Fans were made. People used to believe that evil was everywhere, and that evil needed to be driven away. Nara Fans are made of bamboo and Japanese washi-paper, not made with plastic materials. Nara Fans are sophisticated and expensive. They are a special product of Nara which is very popular among foreigners. The lesson teaches regionalism to students. It also contributes to cross-cultural education and global education. To inherit the traditional craft from a craftsman is difficult. Students continued to think about what can be done about this succession crisis.

Furthermore, during the lesson four questions were raised which warrant further research:

How should we study the ruins of Heijokyo Palace or the ruins in Asuka in Nara?

What can we do to improve the situation of Nara Fans regarding the lack of successor?

How do special products of Nara affect the international community and how should Nara Fans be advertised abroad?

Did the students understand the contents and language naturally through experiencing the English CLIL lesson?

Particularly, the last question addresses the students' understanding of the CLIL lesson. Through analyzing the post-test results, just over $70 \%$ of the students reported that they understood the lesson content. However, about $10 \%$ of them indicated that they found the lesson difficult. Regardless of whether students struggle with English or not, and independent of which language is chosen for instruction, it is imperative that they understand the lesson. Improvement must be made in this regard.

To improve the lesson, students' reactions and comments should be analyzed. First, comments regarding 
"content" (the material of the lesson) were generally positive. Feedback about "communication" (target expressions) was less positive: some students who generally struggle with English answered that the class was difficult. Next, questions regarding cognition (the design, tradition, and development of Nara Fans) and Community/culture (group activity, a specialty, a point of contact with a foreign country) were asked. These generally received positive answers; however, the students had some difficulties thinking deeper about the present situation of Japanese traditional crafts. To minimize the gap between the aim of the instructors and the reactions of the students, the instructor should be aware of the need to repeat the vocabulary and the target expressions more often during the lesson.

\section{Discussion}

During the lesson, the researcher and instructors observed that none of the students were unable to design and make a fan, and likewise none that did not understand the contents at all. They designed and created their fans together with their friends and with their teacher's support.

The question related to "English" has a lower numerical value compared to other questions, and the result of the post questionnaire showed that there were some students who already had an aversion to English.

In communication, language ambiguity should not be necessarily a hindrance. When communicating in a foreign or second language it is often impossible to understand all the words we hear. To imagine what people are talking about from visual aids such as gestures is necessary, and through hearing vocabulary and observing corresponding gestures, learning can take place.

Although there were some students who expressed an aversion to English, most of the students answered that the "Nara Fan" lesson in English was fun. This led the researcher to conclude that the CLIL lessons were particularly valuable for the students who struggle with English.

The two aims of this study are (1) to develop, prepare and present a CLIL lesson instructing students how to make Nara Fans, which are a traditional product of Nara, Japan, and (2) to examine how elementary school students learn about Japanese traditional crafts and think about the development and the sustainability of Nara Fans through the CLIL lesson. In this study, the following results of three research questions were obtained: Regarding RQ1: Did the students learn the target English vocabulary and expressions? As the students were observed using vocabulary such as "Nara Fan", "Washi-paper", and "Paste" during the lesson it is concluded that the students did learn and retain the target vocabulary and expressions. Through the help of visual aids, the students were unconcerned with the language of instruction, and instead concentrated on the lesson content. Although students used their mother tongue in the lesson, they also used English during the activities. That is natural considering that they are at the beginning stage of English study and this will improve as their English progresses. RQ2 asked Did the students learn about the history and use of Nara Fans? The students learned that Nara Fans have a long history, that Nara is popular among foreigners and that they have many ruins in their surrounding areas. RQ3: How did the students learn about Japanese traditional crafts of Nara? From the quantitative analysis, it is concluded that through the Nara Fan lesson the students learned about the importance and the issues facing Japanese traditional crafts.

Before the lesson, CLIL teachers felt anxious about the ability of the students to fully understand the lesson content, but students in fact understood well and enjoyed the lesson. There are two limitations to this research: One is that the questionnaire became available only after the lesson was finished, so it was impossible to compare pre- and post-data. The other point is that although the homeroom teachers were present during the lesson and were able to help, the CLIL instructors were limited regarding individual attention and support for each student.

In conclusion, CLIL lessons should be continued in various subjects, with a variety of subject matter to improve the quality of the lesson, while taking into consideration individual support for each student, and the importance of constant verification of lesson targets and content.

\section{Lesson co-operators (Instructors)}

SAKAI, Sumiko (Osaka Seikei University)

TAKEUCHI, Nicole Marie (Osaka Seikei University)

ITO, Takumi (Nara University of Education graduate school)

\section{Acknowledgements}

This work was supported by JSPS KAKENHI Grant Number JP17H07274. Thank you very much for Ms. Fujito Masayo, teachers, and students in Sango Elementary school, Nara, Japan. 


\section{References}

Coyle, D. (1999). Theory and planning for effective classrooms: Supporting students in content and language integrated learning contexts. In J. Masih (Ed.), Learning through a foreign language (pp. 46-62). London: CILT, Key data on teaching languages at schools in Europe. (2008) Brussels: Eurydice network.

Coyle, D., Hood, P., \& Marsh, D. (2010). CLIL: Content and language integrated learning. Cambridge University Press.

Ikeda, M. (2018). CLIL de sodatsu gakuryoku: gengo chishiki kara hanyou nouryoku made, Dai ikkai J-CLIL Nishinihonkenkyuu taikai koutou happyou shiryou.

Ito, Y. (2018). Kankakukikan to umamino CLIL (naiyougengo tougougata gakushuu)wo tooshite erareru shou/ chuugakusei no ibunka ni taisuru manabi ni tsuite no kousatu [A Study of Cross-cultural Learning Patterns within Elementary School and Junior High School Students through CLIL on the Sensory Organs and Umami.], Osaka-Kyoiku University Shotou kyouiku kouza jissen gakkou kyouiku kenkyuu, 20, 9-18.

Kashiwagi, K., Lee, S., \& Ito, Y. (2018). The effectiveness of Formulaic Sequences on Acquisition of the English Passive Voice: Using Dictogloss Tasks in Form-Focused Instruction. Proceedings of 18th Hawaii International Conference on Education, 167-197.

Kashiwagi, K., \& Tomecsek, J. (2015). How CLIL classes exert a positive influence on teaching style in student centered language learning through overseas teacher training in Sweden and Finland. Procedia, 173, 79-84. https://doi.org/10.1016/j.sbspro.2015.02.034

Marsh, D. (2002). CLIL-EMILE-The European Dimension: Actions, Trends and Foresight Potential. Brussels: European Commission.

Ministry of Education, Culture, Sports, Science and Technology (MEXT). (2015). Course of Study.

Otani, T. (2011). Steps for Coding and Theorization - Meiji teki tetsuzuki de chakushu shiyasuku shokibo deta ni tekiyo kano na shitsuteki deta bunseki shuho- [SCAT: steps for coding and theorization Qualitative data analysis method with explicit procedure, easy to set about, suitable for small scale data]. Kansei Engineering, 10(3), 155-160.

Sasajima, S. (2011). CLIL: Atarashii hasso nojugyo [CLIL: New Ideas for Classes] Tokyo: Sanshusha.

Watanabe, Y, Ikeda, M., \& Izumi, S. (Eds.) (2011). CLIL (Naiyo gengo togogata gakushu) [CLIL: New Challenges in Foreign Language Education, vol.1.]. Tokyo.

Yamano, Y. (2013). Utilizing the CLIL approach in Japanese primary school: A comparative of CLIL and EFL Lessons. The Asian EFL Journal, 15(4), 160-183.

\section{Copyrights}

Copyright for this article is retained by the author(s), with first publication rights granted to the journal.

This is an open-access article distributed under the terms and conditions of the Creative Commons Attribution license (http://creativecommons.org/licenses/by/4.0/). 